http://jmscr.igmpublication.org/home/ ISSN (e)-2347-176x ISSN (p) 2455-0450 crossref DOI: https://dx.doi.org/10.18535/jmscr/v7i8.109

Journal Of Medical Science And Clinical Research

\title{
Correlation between Amniotic Fluid Index and Perinatal Outcome in Term Pregnancy
}

\author{
Authors \\ Rajesh Mohanty, Monalisa Subudhi*, Khetrabasi Subudhi \\ MKCG Medical College and Hospitals, Berhampur \\ *Corresponding Author \\ Monalisa Subudhi
}

Assistant Professor, Dept of microbiology, Gayatri Vidya Parisad Institute of Health care and Medical Technology, Visakhapatnam, Andhrapradesh, 530048

\begin{abstract}
Objective: The purpose of this study was to study and compare the perinatal outcome and mode of delivery in women with oligohydramnios, normal AFI and polyhydramnios group at term gestation having no complication.

Methods: This was a prospective study of 600 singleton pregnancies with gestational age between 37 to 42 weeks without any complicating factor. The AFI was determined in all cases using four quadrant technique. The cases were divided in 3 groups based on their AFI; AFI $\leq 5$ (Oligohydramnios), AFI>5-24, AFI $\geq 25$ (Polyhydramnios). Maternal outcome in form of mode of delivery, abnormal fetal heart rate and cesarean section for fetal distress were studied and perinatal outcome in the form of meconium stained liquor, apgar score at 1 and 5 minute, birth weight, NICU admissions were studied.

Results: The groups had no statistical difference in age, parity, gestational age. There was no statistical difference in regards to MSL,NICU admissions, less apgar score at 1 and 5 minute, birth weight <2.5kg, non reassuring fetal heart rate, indications for cesarean sections. But the group with oligohydramnios had more number of cesarean sections which was statistically significant.

Conclusion: Oligohydramnios with AFI less than or equal to 5 is associated with statistically significant high cesarean delivery rate.
\end{abstract}

\section{Introduction}

Being pregnant is one of the most rewarding phase in woman's life. Nurturing a human inside can most definitely be termed as an adventure. And every day in this adventure is exhilarating and blissful. Modern obstetrics is concerned with the health and wellbeing of both the mother and unburn child. Recognition of a fetus at risk for death or damage in utero, quantifying the risk, balancing fetal risk against neonatal complications from immaturity and determining the optional time and mode of intervention are the cornerstones of modern perinatal medicine ${ }^{(1)}$.

Amniotic fluid (AF) is an important part of pregnancy sac and helps in fetal development. It supports development of musculoskeletal system by permitting fetal movements in addition to growth and development of gastrointestinal system by swallowing amniotic fluid ${ }^{(2)}$. It surrounds the fetus and protects it from trauma, maintains body temperature and it has bacteriostatic properties. Its pressure helps in 
reducing the loss of lung fluid and assist in pulmonary development ${ }^{(3)}$. It helps in dilatation of cervix and prevents cord compression ${ }^{(4)}$.

Amniotic fluid volume (AFV) varies with gestational age from $200 \mathrm{ml}$ at $16 \mathrm{wks}, 1000 \mathrm{ml}$ at $28 \mathrm{wks}, 900 \mathrm{ml}$ at $36 \mathrm{wks}$ and $800 \mathrm{ml}$ at $40 \mathrm{wks}$ of gestation $^{(5)}$. There are various reported ultrasonographic modalities to assess AFV like (1) single deepest pocket (2) Two diameter pocket (3) AFI by 4 quadrant method described by Phelan et al in $1987^{(6)}$. Among them AFI is popular and reliable method of quantifying amniotic fluid till today.

Decrease in amniotic fluid is known as oligohydramnios which complicate about $1-5 \%$ of pregnancies at term ${ }^{(7)}$. Oligohydramnios is considered severe when the value of AFI is less than $5 \mathrm{~cm}$.AFI between 5 to 8 is termed as borderline oligohydramnios ${ }^{(7,9)}$. Oligohydramnios may develop in any triamester but found more commonly at $3^{\text {rd }}$ trimester. About $12 \%$ woman may develop oligohydramnios after 42 wks due to receding placental function ${ }^{(10)}$.Decrease value of AFI has been associated with increased risk of intrauterinme growth retardation, birth asphyxia, meconium aspiration syndrome, low APGAR score and risk of congenital anomalies ${ }^{(11,12)}$. Oligohydramnios is also associated with maternal morbidity in terms of increased rates of induction and operative interventions ${ }^{(13,5)}$.

The condition where abnormal increase in amniotic fluid volume or AFI $>24 \mathrm{~cm}$ is called polyhydramnios $^{(13)}$. It complicates $1-2 \%$ pregnancies $^{(14)}$. Approximately 50-60\% of polyhydramnios cases are idiopathic. Part of polyhydramnios cases is attributed to fetal anomalies, fetal infection, fetomaternal hemorrhage, maternal diabetes.(15). The adverse perinatal outcome include preterm labor. premature rupture of membrane, cord prolapsed etc.

Thus either increase or decrease in AFI leads to adverse perinatal outcome. So keeping this in view by doing serial ultrasonographic estimation of $\mathrm{AFV}$ in the form of AFI from $2^{\text {nd }}$ and $3^{\text {rd }}$ trimester of pregnancy provides a correct information about fetal conditions and play a significant role in obstetric management, timely delivery and subsequent fetal outcome.

In our study we included 600 cases and they were divided in three groups according to amniotic fluid index. We compared the perinatal outcome and mode of delivery between the groups.

\section{Material and Methods}

The study was undertaken in MKCG medical college and hospital, Berhampur. This was a perspective study from October 2016 to September 2018.The inclusion criteria were singleton term gestation with cephalic presentation, having AFI measurement within one week of delivery, without any medical and obvious obstetric complications. Exclusion criteria were known fetal and chromosomal anomalies, placental anomalies, multiple pregnancies, premature rupture of membrane, presence of other medical and obstetrics complications.

For all the selected cases detailed history was taken and clinical examination was performed and gestational age assessed. For all the women, ultrasound examination was done and amniotic fluid index was calculated by four quadrant technique after informed consent was obtained.

Women were divided into three groups based on their AFI: Group1-AFI $\leq 5$; Group 2- AFI >5-24; Group 3- AFI $\geq 25$

Depending upon obstetric factors, investigations and clinical assessment decision for elective cesarean section and induction of labour was taken. Patients with spontaneous and induced labour were monitored.

Maternal outcome in the form of mode of delivery, labour related events like abnormal fetal heart rate and cesarean section for fetal distress were studied. Perinatal outcome in the form of APGAR score at 1 minute and 5 minute, birth weight, meconium staining of liquor and NICU admissions were studied. Results were tabulated and statistically analyzed. $\mathrm{P}$ value less than 0.05 was considered statistically significant. 


\section{Results and Observations}

The following observations are made and plotted in tabulated form.

Table-1 Age in Relation To AFI

\begin{tabular}{|l|c|c|c|c|}
\hline \multirow{2}{*}{ AGE } & \multicolumn{3}{|c|}{ AFI } & TOTAL \\
\cline { 2 - 4 } & $\leq 5$ & $>5-24$ & $\geq 25$ & \\
\hline$<20$ YEARS & $36(18.18 \%)$ & $54(13.85 \%)$ & $2(16.67 \%)$ & 92 \\
\hline $20-29$ YEARS & $150(75.76 \%)$ & $306(78.46 \%)$ & $9(75 \%)$ & 465 \\
\hline$\geq 30$ YEARS & $12(6.06 \%)$ & $30(7.69 \%)$ & $1(8.33 \%)$ & 43 \\
\hline TOTAL & 198 & 390 & 12 & 600 \\
\hline
\end{tabular}

$\mathrm{P}=0.68$

Table-2 (Gravida distribution in relation to AFI)

\begin{tabular}{|l|c|c|c|c|c|c|}
\hline \multirow{2}{*}{ GRAVIDA } & \multicolumn{2}{|c|}{ AFI $\leq 5$} & \multicolumn{2}{c|}{ AFI $>5-24$} & \multicolumn{2}{c|}{ AFI $\geq 25$} \\
\cline { 2 - 7 } & No & $\%$ & No & $\%$ & no & $\%$ \\
\hline G1 & 101 & 51.01 & 203 & 52.05 & 5 & 41.67 \\
\hline G2 & 69 & 34.85 & 116 & 29.74 & 3 & 25 \\
\hline G3 or above & 28 & 14.14 & 66 & 18.21 & 4 & 33.33 \\
\hline Total & 198 & 100 & 390 & 100 & 12 & 100 \\
\hline P=0.32
\end{tabular}

Table-3 Case Distribution according to AFI

\begin{tabular}{|l|c|c|}
\hline AFI & No of cases & $\%$ \\
\hline$\leq 5$ & 198 & 33 \\
\hline$>5-24$ & 390 & 65 \\
\hline$\geq 25$ & 12 & 2 \\
\hline Total & 600 & 100 \\
\hline
\end{tabular}

Table-4 Gestational Age with AFI

\begin{tabular}{|l|c|c|c|c|}
\hline $\begin{array}{l}\text { Gestational } \\
\text { Age }\end{array}$ & \multicolumn{3}{|c|}{ AFI } & Total \\
\cline { 2 - 4 } & $\leq 5(\mathrm{n}=198)$ & $>5-24(\mathrm{n}=390)$ & $\geq 25(\mathrm{n}=12)$ & \\
\hline$\leq 40$ weeks & $138(69.70 \%)$ & $244(62.56 \%)$ & $12(100 \%)$ & 394 \\
\hline$>40$ weeks & $60(30.30 \%)$ & $146(37.44 \%)$ & 0 & 206 \\
\hline $\mathrm{p}=0.08$
\end{tabular}

Table-5 Mode of delivery with relation to AFI

\begin{tabular}{|l|c|c|c|c|}
\hline \multirow{2}{*}{ Mode of delivery } & \multicolumn{3}{|c|}{ AFI } & \multirow{2}{*}{ TOTAL } \\
\cline { 2 - 4 } & $\leq 5$ & $>5-24$ & $\geq 25$ & \\
\hline Cesarean & $177(89.39 \%)$ & $144(36.92 \%)$ & $3(25 \%)$ & 324 \\
\hline Normal & $21(10.61 \%)$ & $246(63.08 \%)$ & $9(75 \%)$ & 276 \\
\hline Total & 198 & 390 & 12 & 600 \\
\hline $\mathrm{p}=<0.00001$ & \multicolumn{4}{|l}{}
\end{tabular}

Table-6 Birth weight with relation to AFI

\begin{tabular}{|l|c|c|c|c|}
\hline \multirow{2}{*}{ BIRTH WEIGHT } & \multicolumn{3}{|c|}{ AFI } & \multirow{2}{*}{ TOTAL } \\
\cline { 2 - 4 } & $\leq 5$ & $>5-24$ & $\geq 25$ & \\
\hline$<2.5 \mathrm{~kg}$ & $75(37.87 \%)$ & $126(32.31 \%)$ & $3(25 \%)$ & 204 \\
\hline$\geq 2.5 \mathrm{~kg}$ & $123(62.13 \%)$ & $264(67.69 \%)$ & $9(75 \%)$ & 396 \\
\hline Total & 198 & 390 & 12 & 600 \\
\hline $\mathrm{p}=0.32$ & \multicolumn{4}{l}{} \\
\hline
\end{tabular}

Table-7 AFI with Meconium Stained Liquor

\begin{tabular}{|l|c|c|c|}
\hline \multicolumn{1}{|c|}{ AFI } & No of cases & Meconium stained liquor & Without meconium stained liquor \\
\hline$\leq 5$ & 198 & $63(31.81 \%)$ & $135(68.19 \%)$ \\
\hline$>5-24$ & 390 & $114(29.23 \%)$ & $276(70.77 \%)$ \\
\hline$\geq 25$ & 12 & 0 & $12(100 \%)$ \\
$\mathrm{p}=0.21$ & \multicolumn{3}{|c}{}
\end{tabular}


Table-8 Indication for Cesarean Section with Relation to AFI

\begin{tabular}{|l|c|c|c|c|c|}
\hline \multirow{2}{*}{ Indication for cesarean } & \multicolumn{3}{|c|}{ AFI } & \multirow{2}{*}{ Total } & \multirow{2}{*}{-value } \\
\cline { 2 - 4 } & $\leq 5$ & $>5-24$ & $\geq 25$ & & \\
\hline Non reactive FHR & $114(64.01 \%)$ & $86(59.72 \%)$ & & 200 & \multirow{2}{*}{0.55} \\
\hline CPD & $54(30.51 \%)$ & $52(36.11 \%)$ & 3 & 109 & \\
\hline Failed induction & $9(5.08 \%)$ & $6(4.17 \%)$ & & 15 & \\
\hline Total & 177 & 144 & 3 & 324 & \\
\hline
\end{tabular}

Table-9 NICU Admission according to AFI

\begin{tabular}{|l|c|c|}
\hline AFI & No of cases & NICU admission \\
\hline$\leq 5$ & 198 & 36 \\
\hline$>5-24$ & 390 & 48 \\
\hline$\geq 25$ & 12 & 0 \\
\hline Total & 600 & 69 \\
\hline $\mathrm{p}=0.098$
\end{tabular}

Table-10 (Apgar Score @ 1MIN)

\begin{tabular}{|l|c|c|c|c|c|}
\hline \multirow{2}{*}{ Apgar@1min } & \multicolumn{3}{|c|}{ AFI } & \multirow{2}{*}{ Total } & \multirow{2}{*}{ P value } \\
\cline { 2 - 4 } & $\leq 5$ & $>5-24$ & $\geq 25$ & & \\
\hline$<7$ & $37(18.69 \%)$ & $51(13.08 \%)$ & 0 & 93 & \multirow{2}{*}{0.14} \\
\hline$>7$ & $156(81.31 \%)$ & $339(86.92 \%)$ & $12(100 \%)$ & 507 & \\
\hline Total & 198 & 390 & 4 & 600 & \\
\cline { 1 - 4 } $\mathrm{p}=0.14$
\end{tabular}

Table-11 (Apgar Score @ 5 MIN)

\begin{tabular}{|l|c|c|c|c|c|}
\hline \multirow{2}{*}{$\begin{array}{l}\text { Apgar } \\
\text { score @ 5min }\end{array}$} & \multicolumn{3}{|c|}{ AFI } & Total & $\begin{array}{c}\text { P } \\
\text { value }\end{array}$ \\
\cline { 1 - 5 } & $28(14.14 \%)$ & $42(10.77 \%)$ & 0 & 70 & 0.44 \\
\hline$>7$ & $170(85.86 \%)$ & $348(89.23 \%)$ & $12(100 \%)$ & 530 & \\
\hline$>7$ & 198 & 390 & 12 & 600 & \\
\hline Total & \multicolumn{5}{|l}{} \\
$\mathrm{p}=0.44$
\end{tabular}

Outcome Parameters in Study Population

\begin{tabular}{|l|c|c|c|c|c|c|}
\hline \multirow{2}{*}{ Outcome parameters } & \multicolumn{2}{|c|}{ Oligohydramnios group } & \multicolumn{2}{c|}{ Normal AFI group } & \multicolumn{2}{c|}{ Polyhydramnios group } \\
\cline { 2 - 7 } & No of patients & $\%$ & No of patients & $\%$ & No of patients & $\%$ \\
\hline MSL & 63 & 31.81 & 114 & 29.23 & - & \\
\hline LSCS & 177 & 89.39 & 144 & 36.92 & 3 & 25 \\
\hline LSCS for fetal distress & 114 & 57.58 & 86 & 22.05 & - & \\
\hline APGAR<7 @1MIN & 37 & 18.69 & 51 & 13.08 & - & \\
\hline APGAR<7 @5MIN & 28 & 14.14 & 42 & 10.77 & - & \\
\hline Birth wt <2.5kg & 75 & 37.87 & 126 & 32.31 & 3 & 25 \\
\hline NICU admission & 36 & 18.18 & 48 & 12.31 & - & \\
\hline Neonatal death & 2 & 1.01 & 2 & 0.51 & - & \\
\hline
\end{tabular}

In the above table, perinatal outcome of three AFI groups are shown. There were total 198 patients in oligohydramnios group, 390 patients in normal AFI group and 12 patients in polyhydramnios group.

\section{Discussion}

The present study was carried in the dept. of $\mathrm{O} \&$ $\mathrm{G}$ to compare the perinatal outcome and mode of delivery in uncomplicated term pregnancies with oligohydramnios, normal AFI and polyhydramnios group. Total 600 cases were studied, of which 198 cases had $\mathrm{AFI} \leq 5,390$ cases had $\mathrm{AFI}>5-24$ and 12 cases had $\mathrm{AFI} \geq 25$.

Age wise distribution in the study showed that in the group with oligohydramnios mean age was 23.32, for the group with normal AFI was 23.56, for the group with polyhydramnios was 25.3.The 
difference between the mean age between the groups was not statistically significant ( $p$ value $=0.68$ ). Menka verma et al conducted a similar study comparing pregnancy outcome in two groups of $\mathrm{AFI} \leq 5$ and $\mathrm{AFI}>5$ and the results were comparable to our study with mean age being 25.98 and 26.1 respectively in two groups and no statistical difference between the mean age in two groups. $(p \text { value }=0.76)^{(15)}$.

In our study $51.01 \%$ women in the oligohydramnios group was nulliparous, $34.85 \%$ had parity $\mathrm{P} 1,14.14 \%$ had parity $\mathrm{P} 2$ or more; in the group with normal AFI $52.05 \%$ were nulliparous, $29.74 \%$ had parity $\mathrm{P} 1,18.21 \%$ had parity $\mathrm{P} 2$ or more. In polyhydramnios group five cases $(41.67 \%)$ were nulliparous, three $(25 \%)$ were primipara, four $(33.33 \%)$ had parity $\geq \mathrm{P} 2$. There was no statistical difference in parity among groups $(\mathrm{p}=0.32)$.Overall $51.5 \%$ cases were nulliparous, $31.33 \%$ cases had parity of $\mathrm{P} 1,17.17 \%$ cases had parity of $\mathrm{P} 3$ or more. Bhagat et al found $68 \%$ women in nulliparous group in oligohydramnios group and 58.9\% women nulliparous in normal AFI group in a study similar to us ${ }^{(16)}$. Pradip R Gaikwad conducted a study and found that $63.2 \%$ women were nulliparous and $36.7 \%$ women were multiparous in group of oligohydramnios. In group of normal AFI $62.7 \%$ cases were nulliparous and $37.2 \%$ cases were multiparous $^{(17)}$. In a study by Richa kansal et al, they found that $64 \%$ patients were nulliparous in the oligohydramnios group ${ }^{(4)}$.

In our study, distribution of gestational age was studied and $69.7 \%$ women in the group of oligohydramnios had gestational age less than or equal to 40 weeks.30.3\% women had gestational age more than 40 wks. In group of normal AFI $62.56 \%$ women below 40 weeks and $37.44 \%$ women belonged to $>40 \mathrm{wks}$. All polyhydramnios cases were $\leq 40$ weeks. No statistical difference between the groups as $\mathrm{p}=0.08$. In another study results were found similar to our study with $76.4 \%$ cases with gestational age less than 40 weeks and $23.5 \%$ with more than 40 weeks in group with oligohydramnios. And $79.4 \%$ cases had gestational age less than 40 and $18.1 \%$ had gestational age more than 40wks in gr 2 with no statistical difference between the groups ${ }^{(18)}$.

In our study, it was found that $89.4 \%$ women underwent cesarean section and $10.6 \%$ women underwent normal delivery in the oligohydramnios group. In group with normal AFI $37 \%$ underwent cesarean and 63\% underwent normal delivery. In polyhydramnios group $25 \%$ patients underwent cesarean delivery. This difference in mode of delivery is found to be statistically significant ( $\mathrm{p}$ value $=0.00001$ ). Pradip $\mathrm{R}$ Gaikwad et al reported cesarean section was performed in $73.4 \%$ in oligohydramnios group and $37.2 \%$ in borderline AFI group ${ }^{(17)}$. Bhagat et al did a similar study where they found $56 \%$ women in oligohydramnios group underwent cesarean section and 35\% women underwent cesarean section in normal AFI group ${ }^{(16)}$. Study by Mangal Puri et al reported $76 \%$ cesarean section in oligohydramnios group and $36 \%$ cesarean section in group with borderline $\mathrm{AFI}^{(5)}$. Garima Gupta et al reported $71 \%$ cesarean rate in oligohydramnios group, $23 \%$ cesarean rate in borderline AFI group, $10 \%$ cesarean rate in Group having AFI 8-24 ${ }^{(19)}$. Chate et al reported that overall cesarean rate was significantly higher in the group with $\mathrm{AFI} \leq 5$ as compared to AFI $>5 \mathrm{~cm}^{(20)}$.

In our study, indication for cesarean section was not reassuring fetal heart rate in $64.01 \%$ and $59.72 \%$ of women in oligohydramnios and normal AFI group respectively. Bhagat et al reported 57\% of all cesarean section in oligohydramnios group $35 \%$ of all cesarean section in normal AFI group due to non reassuring fetal heart rate ${ }^{(16)}$. In another study the common indication for cesarean was similar which reported non reassuring fetal heart rate was responsible for $66 \%$ of all cesarean section in oligohydramnios group and $65 \%$ of all cesarean section in borderline AFI group ${ }^{(5)}$.

We studied the perinatal outcomes and compared the NICU admission between the groups and in our study $18 \%$ of neonates had NICU admission in oligohydramnios group compared to $12.31 \%$ 
NICU admission in normal AFI group and there was no NICU admission in polyhydramnios group. The difference was not found to be statistically significant in between the groups $(\mathrm{p}=0.098)$. In a similar study NICU admission was $32 \%$ in oligohydramnios group and $21 \%$ in borderline AFI group ${ }^{(5)}$. In another study NICU admission in oligohydramnios group was $7.8 \%$ and $3 \%$ in borderline AFI group ${ }^{(18)}$. Menka Verma et al reported $20 \%$ NICU admission in oligohydramnios group and 6\% NICU admission in normal AFI group ${ }^{(15)}$. Chate et al also reported that the incidence of admission to NICU was significantly higher in $\mathrm{AFI} \leq 5 \mathrm{~cm}$ group ${ }^{(20)}$.

There were 4 neonatal deaths in our study,out of which 2 were born to oligohydramnios mother and 2 were born to mother having normal AFI. In oligohydramnios group out of 2 death one due to meconium aspiration syndrome and other due to respiratory distress leading to hypoxic ischemic encephalopathy. In normal AFI group 2 deaths were due to hypoxic ischemic encephalopathy.

We compared apgar score at 1 minute $(<7)$ and at 5 minute $(<7)$ and found that there were $18.69 \%$ neonates in oligohydramnios group and $13.08 \%$ neonates in normal AFI group with apgar score less than 7 at 1 minute $(\mathrm{p}=0.14) .14 .14 \%$ neonates of oligohydramnios group and $10.77 \%$ neonates in normal AFI group had apgar score less than 7 at 5 minute

$(\mathrm{p}=0.37)$ and the difference was not found statistically significant. Similarly to our study Menka verma et al found significant difference in apgar score at 1 minute in both the groups (26\% vs $10 \%)^{(15)}$. Bhagat et al also found difference in apgar score at 1 minute between two groups (36\% vs $11 \%)^{(16)}$. In our study, there was no significant difference in $5 \mathrm{~min}$ apgar score between the oligohydramnios and normal AFI group. Similarly to our study Bhagat et al found no difference in low apgar score at 5 minutes in the two groups ${ }^{(16)}$. In our study, in polyhydramnios group all the 12 neonates delivered had apgar score $>7$ at 1 minute and 5 minute.
In our study, meconium staining of liquor was compared between the groups. $31.8 \%$ women in oligohydramnios group and $29.2 \%$ women in normal AFI group had MSL. In polyhydramnios group all women had clear liquor. Here the difference was not statistically significant. $(p=0.21)$. Mangal Puri et al did a similar study and MSL was found in $28 \%$ women in oligohydramnios group and in $16.36 \%$ in borderline AFI group ${ }^{(5)}$. In study by Menka Verma et al $12 \%$ women had MSL in oligohydramnios group and $14 \%$ women had MSL in normal AFI group and in both studies the difference was not significant ${ }^{(15)}$.

In our study, perinatal outcome in the form of birth weight of the neonates was compared and it was found that $38 \%, 32.3 \%, 25 \%$ neonates had birth weight $<2.5 \mathrm{~kg}$, in oligohydramnios, normal AFI and polyhydramnios group respectively. The difference in birth weight between the groups was not significant in our study $(\mathrm{p}=0.32)$. Sultana et al observed that the difference in low birth weight was not significant between two groups of $\operatorname{AFI}(\mathrm{p}=0.4)^{(11)}$. In a study by Menka verma et al $36 \%$ neonates in oliohydramnios group and $14 \%$ neonates in normal AFI group had birth weight $<2.5 \mathrm{~kg}$ and difference was statistically significant $^{(15)}$. Bhagat et al reported $56 \%$ neonates had birth weight $<2.5 \mathrm{~kg}$ in oligohydramnios group and $21 \%$ neonates had birth weight $<2.5 \mathrm{~kg}$ in normal AFI group and the difference was statistically significant $^{(16)}$.

\section{Conclusions}

It is concluded from the present study that the amniotic fluid index of less than or equal to 5 can be used as an yardstick for intervention in term pregnancy. Abnormal AFI is associated with adverse perinatal outcome in form of higher rate of meconium stained liquor, non reaasuring fetal heart rate, low birth weight, poor apgar score at 1 and 5 minute, NICU admissions and neonatal mortality. Therefore patients with low AFI needed cesarean sections for better perinatal outcome. 
To conclude with determination of AFI is auxiliary to other fetal surveillance methods and oligohydramnios with AFI less than or equal to 5 is associated with statistically significant high cesarean rate.

\section{Reference}

1. Manning FA;Antepartum fetal testing:A critical appraisal, Curr Opin Obst Gynecol.2009;21(4):348-52

2. Ever HF. Comparibility of amniotic fluid index and single deepest pocket measurements in clinical practice; Aus NJ J Obst Gynecol. 2003;43:75-7

3. Nicolini $U$ et al. Low amniotic pressure in oligohydramnios-Is this cause of pulmonary hypoplasia; Am J Obst Gynecol; 1989;161(5): 1098-101

4. Richa Kansal et al. Oligohydramnios: maternal and fetal outcome in pregnant females; Asian Pac J health science; 2017; 4(2):235-240

5. Mangal Puri,Kanika Sharma. Low amniotic fluid index and intranatal and perinatal outcome in term pregnancy; Int $\mathbf{J}$ of Medical and health research; 2017 Nov 3(11):129134

6. Phelan JP et al. Amniotic fluid assesement using four quadrant technique in pregnancy between 36 and 42 weeks gestation; J Reprod Med 1987;32: 540-2

7. Hill LM, Breckle R, Wolfgram KR. O'Brien PC. Oligohydramnios; ultrasonically detected incidence and subsequent fetal outcome. Am J Obst Gynecol 1983;147: 407-10

8. Kwon JY et al. Abnormal Doppler velocitmetry is related to adverse pregnancy outcome for borderline amniotic fluid index in the third triamester. J Obst Gynecol Research 2006;32:545-549

9. Desai PK. Decrease in amniotic fluid index in low risk pregnancy.Any significance? J Obst Gynecol Ind 2004;54(5):464-6
10. Dasari P, Nivedita G. The maximal vertical pocket and amniotic fluid index in predicting fetal distress in prolonged pregnancy; Int $\mathrm{J}$ Obst Gynecol 2007;96(2):89-93

11. Sultana S. Low amniotic fluid index in high risk pregnancy and poor apgar score at birth; J Coll Physicians Surg Pak 2008 Oct;18(10):630-4

12. Harlev A et al. Maternal assesement of fetal weight as a complementary method of fetal assesement:a prospective clinical trial; J Reprod Med 2006 Jul;51(7):515-520

13. Williams obstetrics-Text book $24^{\text {th }}$ edition2014, page 234

14. Magnan EF et al. A review of idiopathic hydramnios and pregnancy outcomes. Obst Gynecol survey 2007;62:795-802

15. Menka Verma et al.Relatioinship of decreased amniotic fluid and perinatal outcome; Int $\mathrm{J}$ of research in medical sciences; 2016 Sept.4(9): 4093-4096

16. Megha Bhagat. Correlation of amniotic fluid index with perinatal outcome; J Obst Gynecol India 2014 Feb;64(1):32-35.

17. Pradip R Gaikward: Perinatal outcomes in oligohydramnios and borderline amniotic fluid index; Int J Reprod Contracept Obst Gynecol 2016 Jun;5(6):1964-1968

18. Akshaya $\mathrm{Ku}$ Mahapatro. Pregnancy outcome following induction of labour in oligohydramnios and borderline liquor at term; J of evolution of medical and dental sciences 2013 Dec;2(52):10289-10294

19. Garima Gupta et al. Relation of intrapartum amniotic fluid index to perinatal outcome:Int $\mathrm{J}$ of Medical Research Professionals 2017;3(3):131-135

20. Chate $P$ et al. Pregnancy outcome after diagnosis of oligohydramnios at term. Int $\mathbf{J}$ Reprod Contracept Obst Gynecol 2013 Mar;2(1):23-26. 